Island Studies Journal, Vol. 6, No. 1, 2011, pp. 29-44

\title{
China's Island Frontier: Geographical Ideas on the Continent-based Nationalist Narratives on Taiwan
}

Peter Kang

Department of Taiwan and Regional Studies

National Dong-hwa University

Taiwan

kang@,mail.ndhu.edu.tw

\begin{abstract}
This paper explores how nationalist narratives from Taiwan grappled with incorporating their 'island frontier' into conceptions of a Chinese unitary state. In the post World War II era, after the Chinese Nationalist government-in-exile re-established itself on the island of Taiwan, US-dominated scholarship strategically framed Taiwan as a convenient substitute for the study of China. This framing went hand in hand with the re-sinicization project on the island vigorously pursued by the Nationalists after they took control over the island after the collapse of the Japanese Empire. The Nationalist agenda emphasized the historical connection between the island and mainland China in order to politically create an imagined, and imagining, national community across the Strait. This paper critically investigates how continent-based nationalist narratives have sought to incorporate offshore islands into their unitary framework. It does so by deploying the concepts of geobody, geomancy, geochronology, geosymmetrical analogies, and regional demarcation to explore the geographical ideas on the construction of the postwar national imaginary.
\end{abstract}

Keywords: China, Chinese nationalism, geographical ideas, island identity, Taiwan

C 2011 Institute of Island Studies, University of Prince Edward Island, Canada.

\section{Introduction}

It was 30 years ago that geographer Ronald G. Knapp edited a collection on the historical geography of Taiwan entitled China's Island Frontier (Knapp, 1980). Going back to the 1970s, the academic world in general did not hesitate to claim the former status of Taiwan as China's frontier when dealing with historical issues related to the island. Use of the term frontier itself is an acceptable common ground for the understanding of the island in relation to China in the period beginning in the late 17th century but it remains open to interpretation as to when the island's frontier status really ended. To some extent, the island's frontier status did not actually come to an end when the newly-industrialized Japan took over Taiwan in 1895, since the Qing Empire of China had previously only been able to effectively control the lowland areas of the island. The mountainous region, which accounts for more than half of the island, was still outside the pale of Chinese civilization. Nevertheless, in the early Cold War era, the island was surprisingly being treated as representative of "traditional" China.

In 1994, sociologist Stephen O. Murray, and a Berkeley-trained chemist, Keelung Hong, sought to offer a critical review of Cold War-era social science research on Taiwan (Murray \& Hong, 1994). Their second book went even further in examining how 


\section{P. Kang}

Taiwanese realities have been represented-and misrepresented-in American social science literature, especially anthropology, in the immediate post-war era. Hong and Murray argued that the mutual interests of the military government of the Republic of China (ROC) and US social scientists were responsible for mischaracterizing Taiwan as being representative of traditional Chinese culture. American anthropologists, eager to study China but denied access by its communist government, turned instead to fieldwork on territory controlled by the ROC, which they incorrectly and disingenuously interpreted to reflect traditional Chinese society on the mainland, overlooking cultural and historical differences between the island of Taiwan and mainland China (Hong and Murray, 2008) ${ }^{1}$.

Hong and Murray's argument critically reflected upon how postwar Taiwan studies were constructed, and suggested new points of departure for reconsidering how the island might be re-configured in the future. Their argument, however, did not evoke significant academic feedback until Paul-François Tremlett wrote the introduction for the inter-disciplinary volume of essays entitled Re-writing Culture in Taiwan, a book of reflections on how Taiwan has been studied and represented in its current state (Tremlett, 2009: 4).

The postwar development of social theory on the island of Taiwan, however, goes beyond what Hong and Murray prescribed. On the one hand, US-dominated international academia strategically framed Taiwan as a convenient proxy for China studies in the immediate postwar era, when the Chinese Nationalist government-in-exile re-established itself on the island and received US support following the outbreak of the Korean War in 1950. We can refer to this way of looking at Taiwan as the China-substitute approach. This approach basically views Taiwan as representing "traditional" China, in contrast to PRC-ruled mainland China, which was undergoing a fundamental socio-economic transformation at the time. On the other hand, the China-substitute approach, being launched from outside Taiwan, could not acquit itself well without the cooperation and collaboration of the government in Taiwan. After the Chinese Nationalist regime took over the island from the Allied-defeated Japanese Empire, the Nationalists vigorously carried out a (re)-sinicization project on the island ${ }^{2}$. Sinicization had already been an ongoing process in Taiwan before the Japanese took the island from the Qing Empire, and it ultimately reached its peak in 1885 when the Empire granted the island provincial status. In terms of (re)-sinicization, in addition to various institutionalized socio-cultural projects, the postwar Nationalist agenda also turned toward emphasizing the connection between the island and mainland China, to politically create an imagined, idealistically homogeneous national community across the

\footnotetext{
1 The mis-representation of traditional Chinese culture does have its precedent. For instance, the Bai, descendants of what was a powerful kingdom called Nanzhao in the eighth century, and who are now the second largest minority group in the Yunnan province of China, were anthropologically famous for being studied as a community considered to be the ideal representation of Chinese society and culture, from the late 1940s through the early 1970s. See David Wu's discussion on the works by Charles Patrick Fitzgerald and Francis L. K. Hsu (Wu, 1991: 166-71).

${ }^{2}$ I use the term (re)-sinicization rather than re-sinicization or sinicization mainly for two reasons: (1) the use of re-sinicazation alone implies that the process had been achieved at a certain historical point, and the postwar agenda was primarily aimed at the clearing-up of "non-Chinese-ness" left behind from the Japanese episode, and the re-introduction of "Chinese-ness"; (2) the use of sinicization alone insinuates that the objective was never achieved in previous stages of history
} 
strait $^{3}$. It was achieved not only by direct government propaganda but also by a socio-cultural sphere imbued with the said ideological narratives. This paper focuses on how geographical concepts and theories are utilized to interpret the relation between an island and its nearby mainland state ${ }^{4}$. For the issue of the island itself, it is critical to understand how continent-based nationalist narratives work to incorporate islands into its framework. I choose the approaches of geobody, geomancy, geochronology, geosymmetrical analogies, and regional demarcation, to explore the geographical ideas prevalent in the postwar national imagination, and thus use the title to Knapp's (1980) work as my inspiration.

\section{From Geobody to Geomancy and Geochronology}

In the immediate postwar era, one of the social theory developments on the island of Taiwan fell into the framework of interpretation of the island's relationship to mainland China. Modern cartography and the mass production of national maps are tools that facilitate the idea of members of an imagined community identifying with its spatial layout (Anderson, 1991: 170-8). Thongchai Winichakul further proposed the term 'geobody' by taking the case of Siam, and arguing that the knowledge of nationhood was created by the idea of a 'nation on the map', in which the new geography and technology of mapping replaced indigenous territory for an emerging national territory (Winichakul, 1994: 17-8). Once the national territory was determined, a metaphor for the shape of national space was also created to enhance the interpretation of national territory.

Following Winichakul's line of thought, the Nationalist idea of the geobody of Republican China is commonly interpreted as comparing the whole of China to the leaf of Begonia grandis; a conceptual abstraction of both a supposedly objective reality and integrity, by virtue of a plant metaphor. Because the naturalness of a leaf is undeniable, the metaphor facilitated the creation of territorial nationhood as inherently natural. Nonetheless, the metaphor of the Begonia grandis leaf is a continent-based idea, which either leaves no room for or downplays the significance of any islands on the nationalist imagination. Maps 1 and 2 are the works of modern cartographers from the Republican era ${ }^{5}$. They both fit with the conceptualization of the Begonia metaphor, with or without the islands situated outside the continent.

\footnotetext{
3 Readers may note the paradox between the China-substitute approach and the (re)-sinicization project. The former accepts Taiwan as authentic representation of China, but the latter does not.

4 The cases being discussed here are more than those from the official government publication. Since Taiwan was under martial law from 1948 to 1987 (Copper, 1996: 85), state control and censorship was quite a norm for cultural policy under the Nationalist regime (Winckler, 1994: 39). The regime also created a structure of ideologically sanctioned positive incentives for cooperation and acquiescence. It is said to be a "collective national-popular will" as a way of enforcing its hegemony over society, as what Gramsci described (Gold, 1994: 49, 66 note 4). Hence, the narratives on China-Taiwan connection not only existed in the era under the martial law but also prevailed into the post-Cold War era. For instance, the case of textbook map, which would be mentioned later, is an example after the Cold War.

5 Map 1 is taken from the $10^{\text {th }}$ edition of Maps of New Situation of China (Zhonghua xinaingshi yilantu), published in 1926 by the Society of World Geography (shijie yudi xueshe) of Shanghai. Map 2 is from the $4^{\text {th }}$ edition of New Provincial Maps of China (Zhongguo fensen xintu), published in 1939 by Shanghai News (Shun Pao or Shenbao). Note the one in 1926 still has the Prime Meridian passing through Beijing.
} 


\section{P. Kang}

In order to overcome the inherent defects of incorporating the islands, the traditional practice of geomancy (feng shui) is desirable to redeem the nationalist narratives. Such redemption was mainly achieved by the discourses on the dragon tendon or dragon vein (longmai), an art of interpretation performed on a mountain and its nearby environments, which also functioned to justify the rightness of both political sovereignty and imperial administration in ancient China (Chou, 2003: 61, 64).

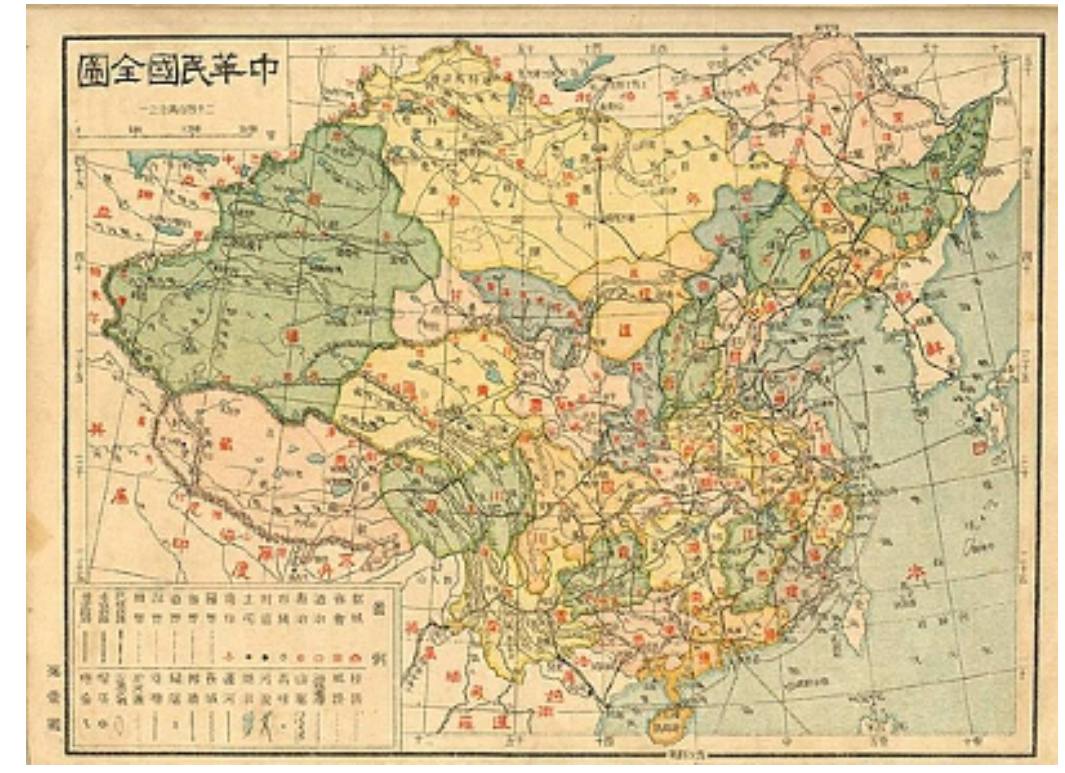

Map 1: Republic of China, published in 1926.

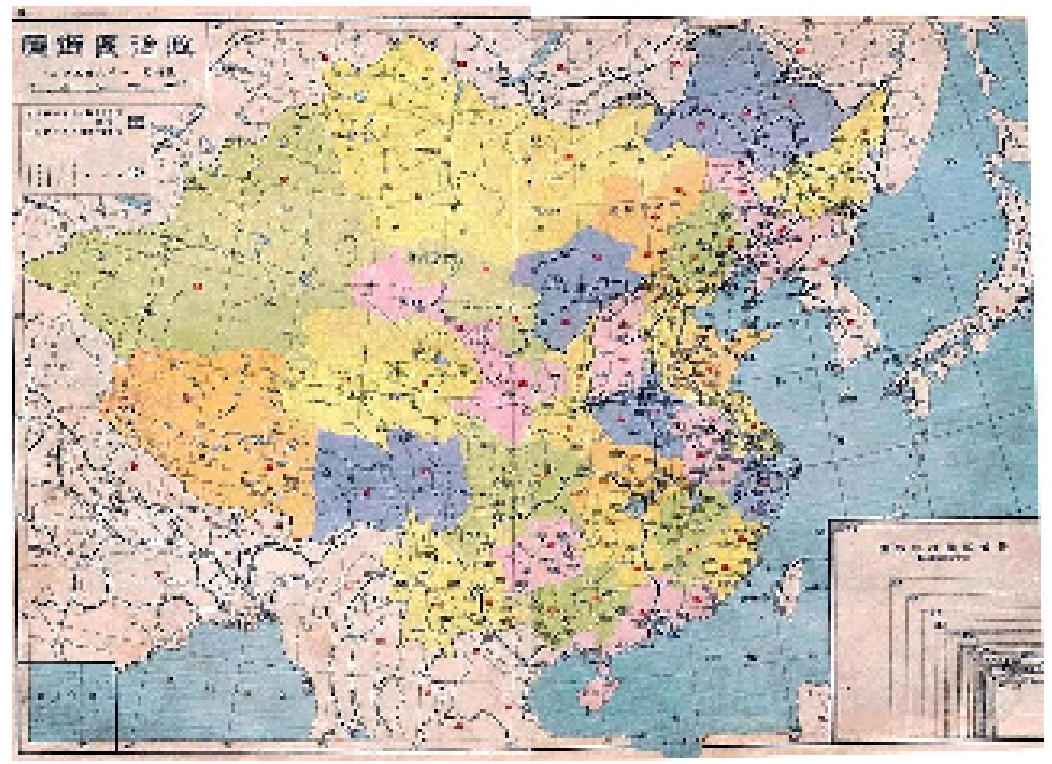

Map 2: Republic of China, published in 1939. 
Taoist geomancy utilizes the metaphor of a geo-organism: it treats stones or rocks as bone, rivers or streams as veins; grass and wood as fur; soil as flesh. The morphology of mountains is the skeletal frame that serves to help interpret the situated place (Chung, 1997: 25). Thus, in terms of geomancy, the interpretation was mainly based on how the topography of a certain place related to these dragon tendons. It is believed that there were three major dragon tendons in China proper, all originating from the Kunlun Mountains of Eastern Turkistan. Nevertheless, the dragon tendons were also a continent-based idea, so all such tendons were theoretically believed to gradually submerge as they ran toward the continental margins. In this sense, seas and oceans became the natural barriers which separated the narrative systems of individual dragon tendons. In other words, we can suppose that each island, if large enough, would have its own narrative system of dragon tendons and would not link to any territories beyond its shores.

The dragon tendon narrative on the island of Taiwan, however, took the approach that salvaged the disconnection. It was said that the dragon tendons of Taiwan originated from those in China. One from Fuzhou was said to "sail into the sea" through the Gate of Five Tigers (Wuhumen), passing through Guantong (today's Nangan and Beigan of the Matsu islands) and Baiquan (today's Dongju and Xiju of the Matsu islands), "be concealed by waves" and finally reach Fowl Cage Mountain (in what is now Keelung) of the main island of Taiwan (TWFC: Kao, 1960: 8). In contrast, another such dragon tendon stretched from Quanzhou to the Pescadores (P'eng-hu Islands), the off-shore archipelago of Taiwan. The dragon tendons were said to submerge into the sea and then reemerge after reaching the islands ${ }^{6}$. Since one of the functions of dragon tendon narratives in the pre-modern imperial stage was to rationalize political sovereignty and imperial administration, in the modern nationalist epoch it still bore a similar function in shaping a nation-state. Map 3 illuminates how the dragon tendon narratives connect the islands to the superior mainland itself ${ }^{7}$.

The dragon tendon narratives faded in prominence as the modern age ushered in the introduction of modern geographical knowledge ${ }^{8}$. We would also be correct in assuming that the advancement of modern geography set aside the pre-modern way of interpretation of linkage, but even the knowledge of modern geography would not conclusively put an end to the interpretation of the natural landscape concerning the connection between the mainland and island. Moreover, the following case demonstrates that pseudo-scientific explanations could go even further, beyond those relying on the visible mountains.

\footnotetext{
${ }^{6}$ Some scholars argued that the paths of so-called sea-submerged dragon tendons, which served to ideologically link Taiwan and China together, were as a matter of fact the sea routes developed by navigators. Thus, unlike aspects of the physical landscape such as mountains (i.e., the dragon tendons high above the sea level), which are visible and subject to fewer versions of interpretation, the exact paths of dragon tendons beneath the sea did vary and were subject to different interpretations (Chou, 2003: 61).

7 The base map came from the "Map of Fujian Province" (Fujian sheng quantu) in Illustrations of Qing Imperial Codes, maps (Qindin da Qing huidiantu, yuditu), ca 1818, reprinted in 1992 by Wen-hai publisher in Taipei. The red lines, standing for the possible paths of dragon tendons, were added later.

${ }^{8}$ For instance, Mount Everest or Qomolangma, is now acknowledged as the highest peak on earth, rather than the Kunlun Mountains; the latter were believed in the pre-modern era to be the ancestral origin of all the mountains (taizushan) in the world. Dragon tendon narratives treat the Alps as the origin of all mountains (zushan) in Europe, and further divide them into four systems: Mont Blanc, the Pyrenees, the Keel (Kölen, Köli or Kjølen), and the Urals. Attention should be paid to the Scottish Highlands, which are said to be connected to the Keel Mountains in the Scandinavian countries (Chung, 1997: 23-25). This interpretation is apparently shaped by the advancement of knowledge in modern marine topography and bathymetry.
} 


\section{P. Kang}

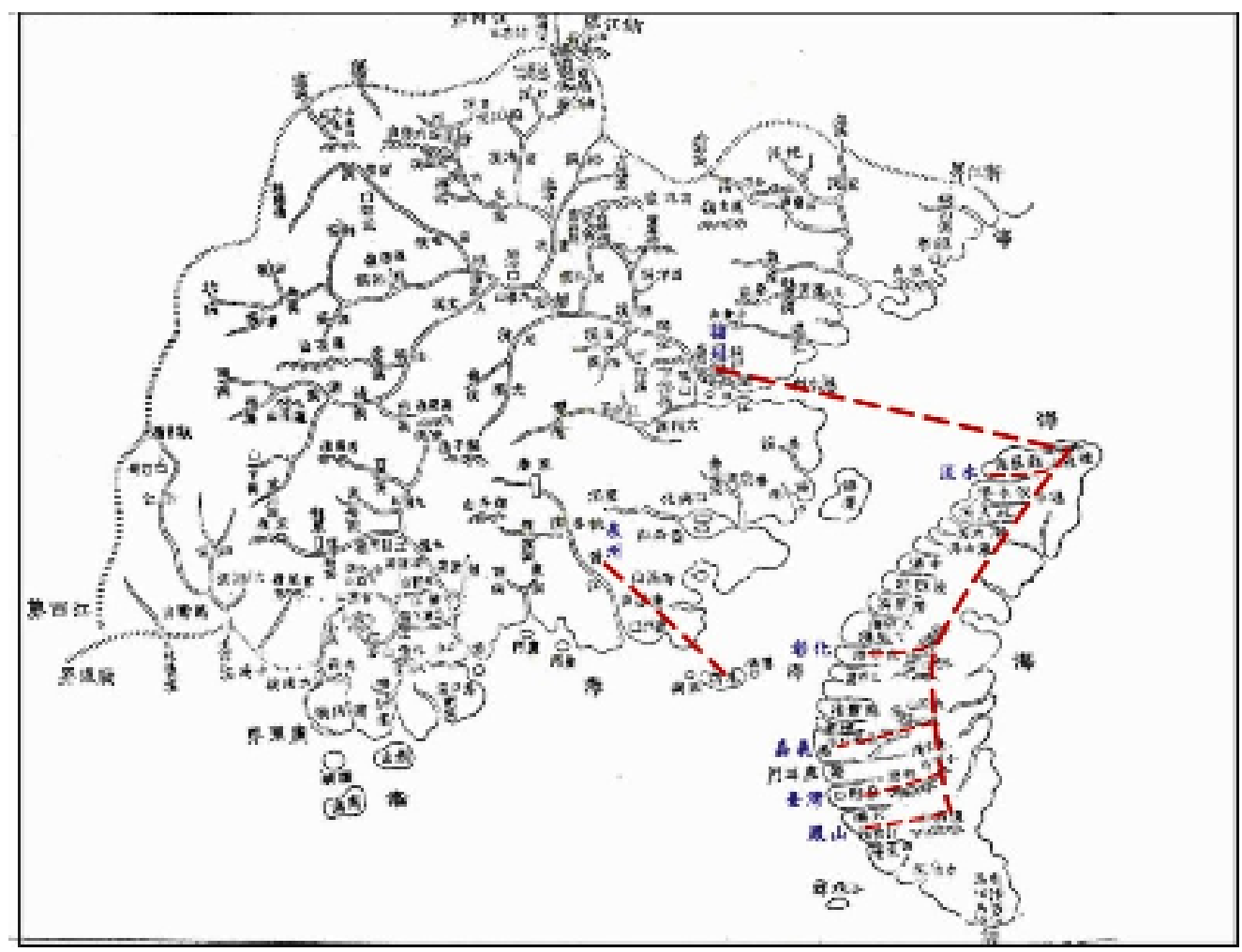

Map 3: Dragon tendons connecting Taiwan and China.

The knowledge of geochronology, especially the extension of the continental landmass into the sea during the epochs of Pleistocene glaciations, was the key. About 18,000 years ago the Pleistocene land bridges connected Japan, Taiwan, and insular Southeast Asia west of Wallace's line to what is today's mainland Asia, and altogether formed a Pleistocene landmass. Submarine topography today, including features such as marine terraces, submarine banks, and submerged valleys (nigu) - turned into hard evidence to support a natural connection between the mainland and islands. We may detect a similar approach in a college-level geography textbook written by a locally-trained geographer in Taiwan, Ho Chin-chu, in the post-Cold War era ${ }^{9}$.

Ho's book on the geography of Taiwan consists of three sections: Part 1 contains an introduction, Part 2 details the physical geography in general, and Part 3 treats the economic and settlement geography. Part 1 consists of three chapters, the first two dealing with the geographical ties and "blood" (xie yuan) relationship between mainland (China) and Taiwan, respectively, whereas the last one details the historical development of Taiwan alone. The chapter on the geographical relation between China and Taiwan

\footnotetext{
${ }^{9}$ Ho Chin-chu holds a Ph.D. in Geography from Chinese Culture University. Ho retired in 1996 from the National Taipei University of Technology and authored several college-level geography textbooks (in Chinese), including Human Geography (1987), Geography of China (1989), and General Geography (1989).
} 
provides a submarine topographical map, which highlights the submerged river valleys in the Taiwan Strait, an ocean channel with an average width of $200 \mathrm{~km}$ separating the island and the Asian Continent (Ho, 1998: 5-6). Readers can easily recognize Ho's cartographical emphasis on the part where the submerged river valleys connect Taiwan and China together, while ignoring those indicating the island's links to other parts in Southeast Asia.

Maps 4, 5 and 6 illustrate how the knowledge of geochronology was appropriated. Map 4 shows the marine topography surrounding the island of Taiwan ${ }^{10}$. Map 5 displays the simplified submarine trenches and canyons, based on the map on the left. Map 6 is taken from one of Ho's geography textbooks, with cartographical emphasis on the linkage between Taiwan and mainland China.

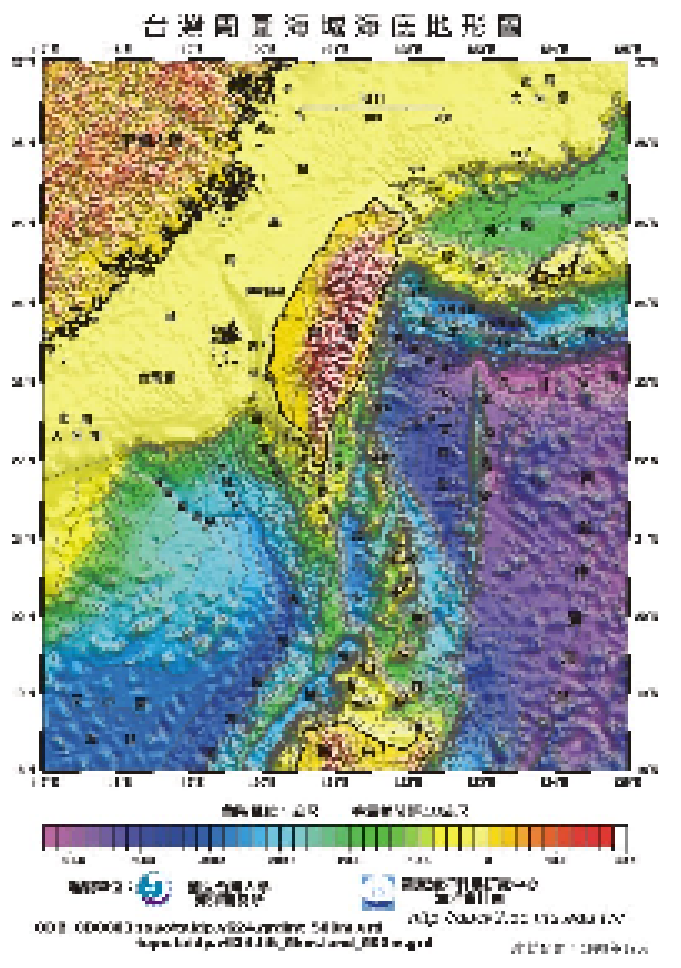

Map 4: Marine topography around Taiwan.

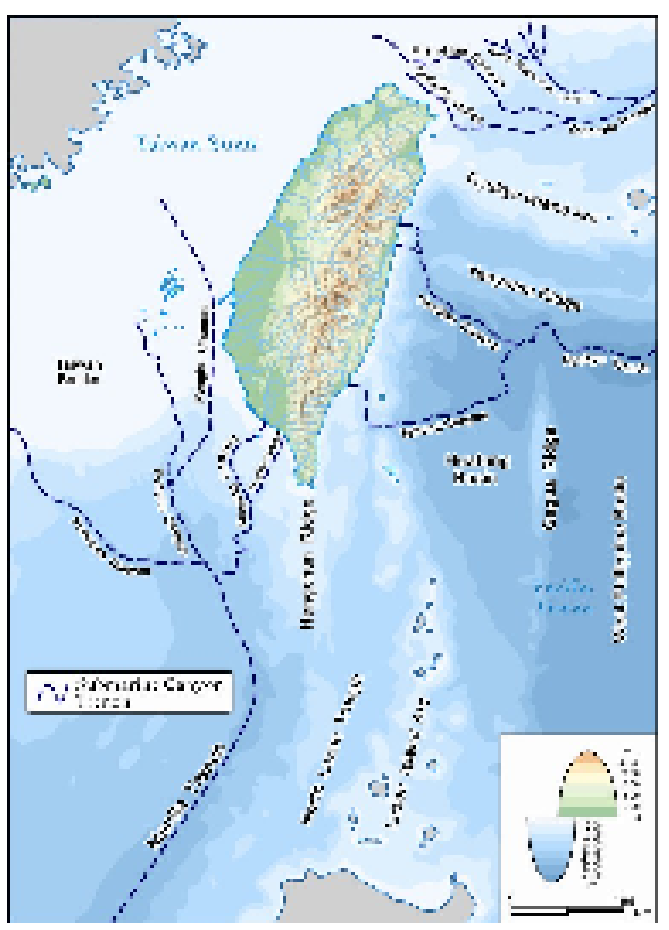

Map 5: Submarine trenches and canyons around Taiwan.

\footnotetext{
${ }^{10}$ Map was produced in 1998 by Institute of Oceanography, National Taiwan University, and Ocean Data Bank, National Center for Ocean Research, Taiwan http://odb.oc.ntu.edu.tw/MGG/mgd/jpg/taidpv624.a4.jpg.
} 


\section{P. Kang}

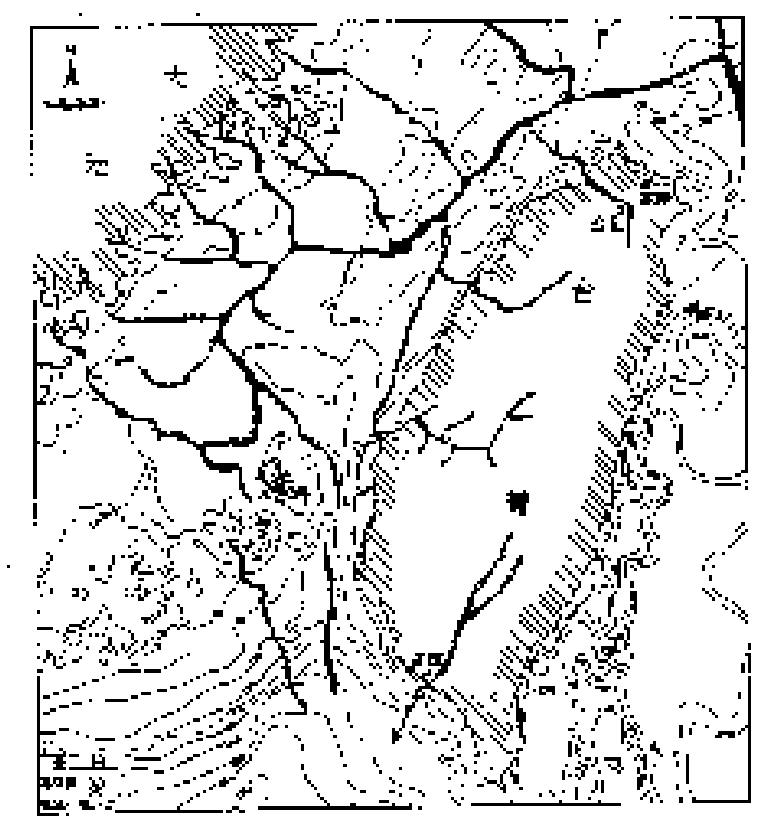

Map 6: Cartographical emphasis of textbooks.

\section{Geosymmetrical Analogies}

To geographers, the approach of geosymmetrical analogies is not new. One popular method is to apply similar climatological conditions prevailing across the same latitude to interpret the relationships between local populations and their environments across similarly situated areas (Markley, 2007: 189-90). This approach later developed into the well-known idea of environmental determinism. As early as the late 17th and early 18th centuries, this approach was also utilized to interpret a certain place by positing its commercial activities within extensive economic cycles of production, trade and consumption $^{11}$. Such an approach facilitated the creation of mental linkage between either far-flung or unrelated areas. In the case of Taiwan, the success of geosymmetrical analogies in interpreting the relation of the island to mainland China relies on the selection and interpretation of other similar cases, that is, of situations involving a continental state and a neighbouring island.

\footnotetext{
${ }^{11}$ For instance, Surinam was outside the commercial circle of Peru and China in the $17^{\text {th }}$ century. In order to create a favourable image on the unwholesome tropical area, geosymmetry became the means not only to idealize the climate of Surinam, but also to point towards extensive economic cycles of production, trade, and consumption (Markley, 2007: 208-15).
} 
In postwar geographer Chen Cheng-siang's 1963 monograph, we come across one such example of a geosymmetrical analogy:

"In the crop year of 1960-61 the world output of sugar was approximately 56.4 million m. t., [...], China is only next to Cuba, Brazil and India, and ranks fourth in the world's sugar-producing countries. If Taiwan alone is taken for comparison, it is the 11th sugar-producing area, roughly on a par with the US-controlled Puerto Rico. Of all the major sugar-producing areas, Taiwan and Puerto Rico have similar conditions. [...] Most of the sugar-exporting areas each have a fixed market, [...] Very peculiar are the cases of Taiwan and Cuba. As likely as not, Taiwan will have to export its sugar to the US mainland, while Cuba will have to export its sugar to the China mainland. This is a most striking example illustrating the impractical arrangements imposed on industries by contemporary politics" (Chen 1963: 339-340). [Italics added]

Chen persuasively argues against the impractical arrangement of market destinations within the postwar political sphere, and further implies a supposedly close relation between the island and the nearby mainland. Hence, the choice of China rather than the US as an export destination for Cuba's sugar was judged as impractical, and, by analogy, the case is made that Taiwan's sugar should be shipped to China rather than the US In making this argument, Chen successfully created an image of linkage between Taiwan and mainland China, through arguing the existence of supposedly close economic ties between the islands and their nearby mainland areas.

The approach of geosymmetrical analogy can bolster premeditated interpretations, but also possesses an inherent potential to backfire. Those with either pro or con agendas for a particular interpretation can easily use this approach to validate their own interpretations. For example, political scientist $\mathrm{Wu}$ Chih-chung, the secretary-general of the European Union Study Association-Taiwan, in a 2006 news article, also employed the case of Cuba to argue for Taiwan's alienation from China by examining the international space of Taiwan and Cuba, two islands facing pressure from China and the US respectively (Wu, 2006).

\section{Regional Demarcation}

The demarcation of a region is a popular method with which many geographers will be familiar. In the case of Taiwan, a well-known example is the historian-dominated interdisciplinary research project sponsored by the National Science Council of Taiwan, which ran from 1973 to 1977, known as the "Regional Study on the Modernization in China (Zhongguo xiandaihua de quyu yanjiu), 1860-1916." 


\section{P. Kang}

The aforementioned research team viewed the modernization of China as a response to encroaching Western powers, and thus employed a temporal framework covering late Imperial China and the early Republican eras. ${ }^{12}$ For the spatial framework the team selected 10 regions with distinguishing geographical features for investigation. They were either along the Yangtze River or on the eastern coast of China, since these locations proved to make them easy prey to outside influence. The chosen 10 regions were Zhili, Shandong, Jiangsu, Shanghai, Guangdong, Hubei, Hunan, Sichuan, Manchuria, and Minzhetai.

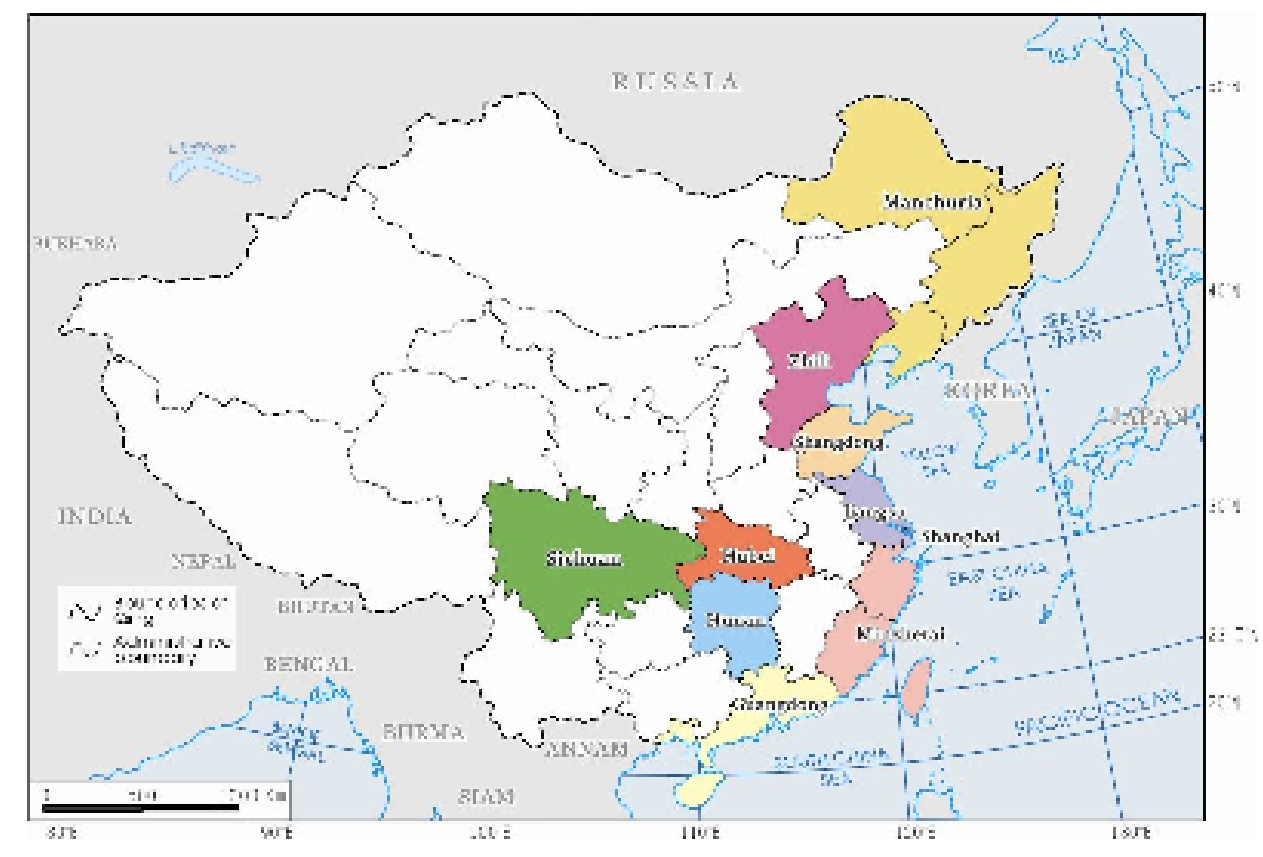

Map 7: Ten regions in the modernization project.

Among the 10 regions listed above, Shanghai is a metropolitan-city, and seven out of the remaining nine are actually provinces in each region. There are two exceptions: Manchuria and Minzhetai. Manchuria was once under the political sovereignty of a Japanese created and controlled entity called Manchukuo, from 1932 to 1945, but previous to that, both the Qing Empire and Republican China divided it into several provinces when the area was under their respective administration. Minzhetai is an agglomeration of two immediate coastal provinces and the island of Taiwan, which obtained its provincial status in 1885 after the Sino-French war. The term Minzhetai itself is the combination of the shorthand for the aforementioned three provinces, in which Min, Zhe, and Tai stand for Fujian, Zhejiang, and Taiwan, respectively.

\footnotetext{
12 The institutionalization of the Office in Charge of Affairs of All Nations (Zongli Geguo Shiwu Yamen) in the Qing Empire after the Second Opium War in 1860 was regarded as the initiative for modernization. On the other hand, the first president of early Republican era (1912-1916) later proclaimed himself as the Great Emperor of China. Thus, Nationalist historians usually viewed the first five years of the Republican era as either an extension of the former Qing Empire or as a transitional stage, and thus interpreted the period as a aberration from their "rule of historical evolution" (lishi yanjin de faze) (Li, 1982: 4).
} 


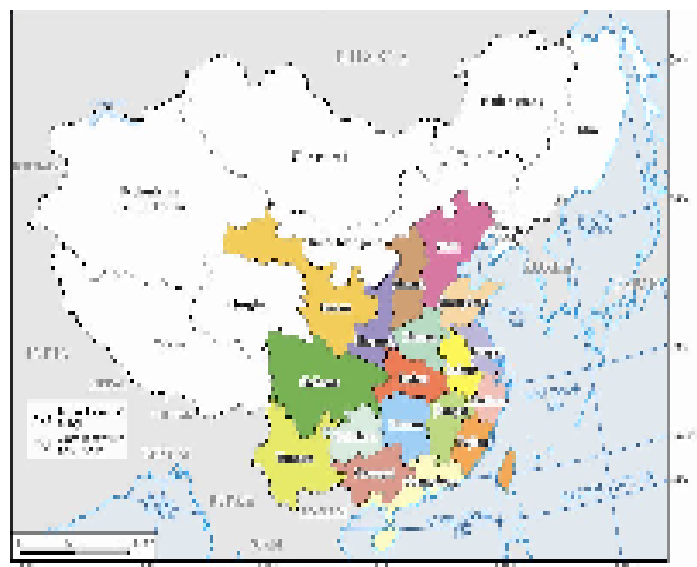

Map 8: Eighteen provinces before 1884.

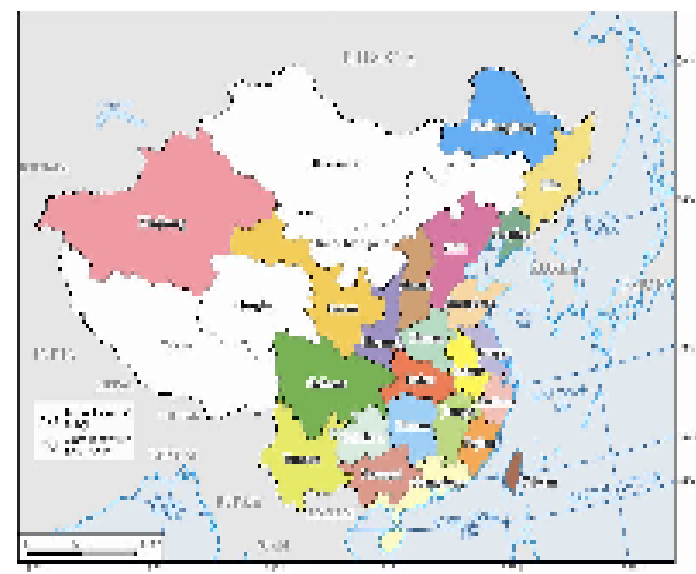

Map 9: Twenty-three provinces in late Qing era.

The creation of the Minzhetai region, according to the research project, was due to the spatial governance under one Governor-General, the Viceroy of Minzhe, within the Qing Empire. The research project further justified its argument by emphasizing the launching of a modernization scheme in the 19th century as a political and administrative rather than geographical matter ( $\mathrm{Li}, 1982$ : 4). The demarcation itself, however, had to face the following challenges.

First, the criteria for the regional demarcation of Minzhetai are not consistent with those used for other cases in the modernization project. The Qing Empire established 18 provinces for China proper in the 17th century, and later added five more provinces by either subdividing existing ones or expanding its imperial territory. The original 18 provinces in China proper were Zhili, Henan, Shangdong, Shanxi, Shaanxi, Gansu, Hubei, Hunan, Guangdong, Guangxi, Sichuan, Yunnan, Guizhou, Jiangsu, Jiangxi, Zhejiang, Fujian, and Anhui. Uyghuristan or East Turkestan was renamed the province of Xinjiang (literally New Frontier) in 1884, Manchuria was subdivided into the provinces of Fengtian, Jilin, and Heilongjiang in 1907, and the island of Taiwan was given its provincial status in 1885. However, in reality the Qing Empire merely had, at most, twenty-two, and not twenty-three provinces under its jurisdiction, because Taiwan was ceded to Japan in 1895 . As for Governor-General, the Emperor only appointed eight for China proper in total, and thus each Governor-General typically administered more than one province. For example, Hubei and Hunan shared one Governor-General, the Viceroy of Huguang; in similar fashion, the Viceroy of Zhili presided over both Zhili and Shandong. Nevertheless, the research project treated these four provinces as four independent regions, rather than two. 


\section{P. Kang}

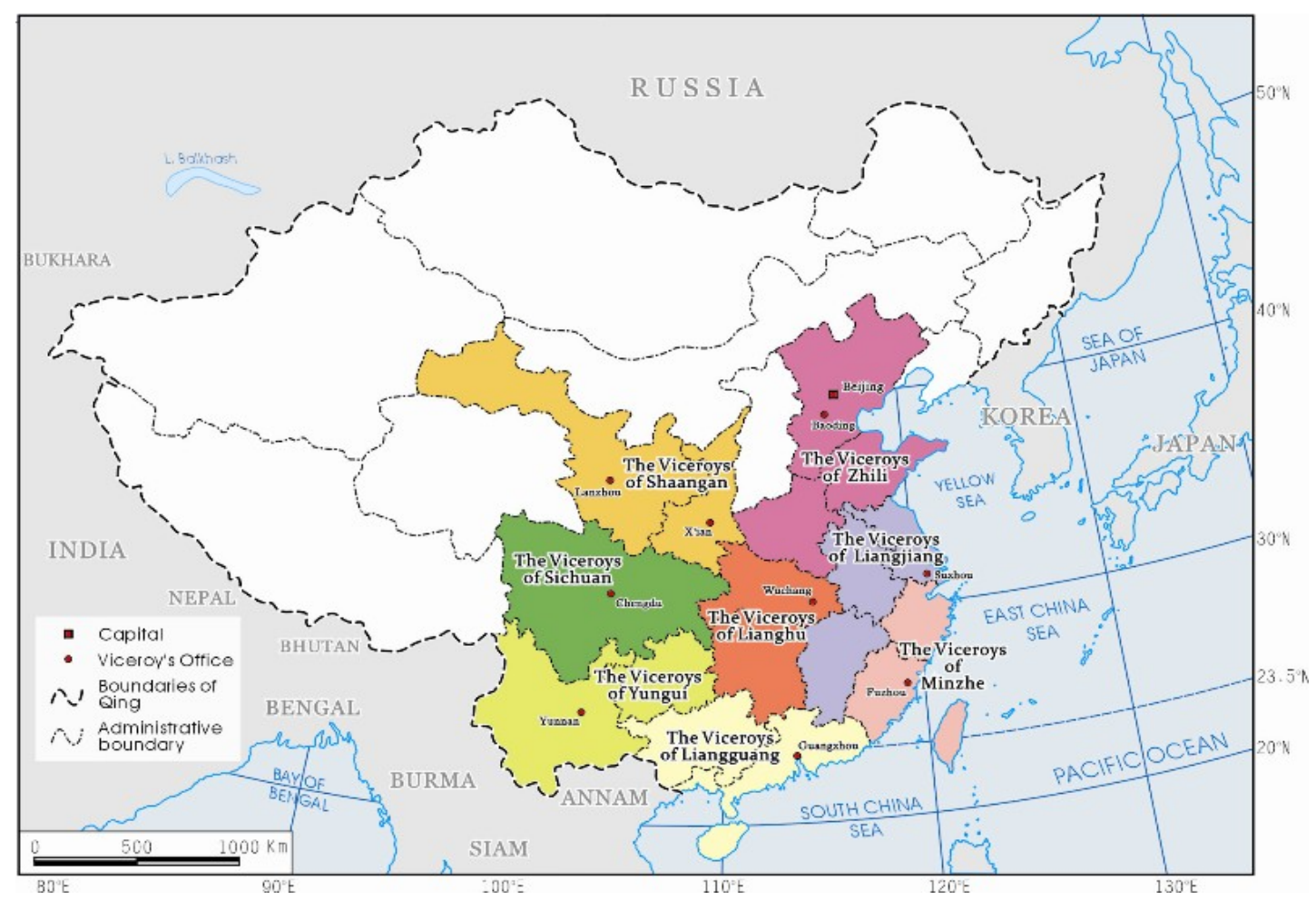

Map 10: Administrative territories of eight Governors-General during the Qing Empire.

Second, the name of the Minzhetai region is a new invention without precedent. The term Minzhe does originate from the title of the Viceroy, but the adding of "Tai" and turning into Minzhetai is definitely an innovation.

The creation of the Minzhetai region, nevertheless, also failed to reflect the reality of late nineteenth century Taiwan in terms of its human geography. Apart from the Austronesian population who were historically related to the peoples of Southeast Asia and Oceania, the rest of the population in Taiwan were mostly from either Fujian (Min) or Guangdong (Yue), while very few were from Zeijiang (Zhe). The research project would like to argue for sinicization through regional integration $(\mathrm{Li}, 1982: 477,527-528,566,576)^{13}$, in which the pre-modern socio-cultural indices were keys to demonstrating that the island's society was transforming itself towards the mainland. ${ }^{14}$ However, the poorly demarcated region Minzhetai merely utilized political and administrative criteria rather than social and cultural ones.

\footnotetext{
13 The research project used the term neidihua, literally translated as transforming toward the inland/interior, to imply the concept of sinicization, where both Sino-centric and continent-based ideas found full expression.

14 Socio-cultural indices for modernization include: the number of local gentry as social leaders, the percentage of local population passing the Imperial examination, the number of Confucian or Christian educational institutes, and the acceptance of worshipped Gods that were highly popular in China proper (Li, 1982: 527-533, 569-573, 589-592).
} 


\section{Conclusion}

Paul-François Tremlett once cited the example of anthropologists in 1981 and decried the human science writings which consistently represented the island of Taiwan as a simulacrum of an imagined traditional Chinese culture (Tremlett, 2009: 6). The current paper takes the case of Taiwan to illustrate how a continent-based nationalist discourse employed geographical concepts for its own sake. I use the approaches of geobody, geomancy and geochronology, geosymmetrical analogies, and regional demarcation to illustrate my point. The characteristics of these approaches are listed in Table 1.

Table 1:

\begin{tabular}{|c|c|}
\hline Approaches & Features \\
\hline Geobody & $\begin{array}{c}\text { A national longing for cartographic form via the exploration of } \\
\text { the deployment of globes, maps, and bodyscapes in patriotic } \\
\text { visual practices }\end{array}$ \\
\hline Geomancy & $\begin{array}{r}\text { Divination via the interpretation of markings. } \\
\text { Unscientific and not academically respected; but enjoying some } \\
\text { degree of popularity as folk belief }\end{array}$ \\
\hline Geochronology & $\begin{array}{r}\text { Creating linkages with the past and projecting links into the } \\
\text { future by establishing millenary presence. } \\
\text { Ideologically selective hard evidence for interpretation }\end{array}$ \\
\hline $\begin{array}{c}\text { Geosymmetrical } \\
\text { Analogies }\end{array}$ & $\begin{array}{c}\text { Vigorous arguments needed, but accompanied with the high risk } \\
\text { of a possible counterargument on the same case. } \\
\text { Ideologically selective hard evidence for interpretation }\end{array}$ \\
\hline Regional Demarcation & Depending on the criteria for its success \\
\hline
\end{tabular}

The island of Taiwan, being a state that has no pre-established nationality under its various governments and their claims to a distinctive political identity, is constantly manoeuvring against the might of an "empire-nation" concept - which includes both current ROC and PRC - and which addresses Taiwan as part of its own self-identification (Bartmann, 2008; Feuchtwang, 2008: 200). Ironically, when the island itself advocates its territorial integrity through a quasi-nationalistic narrative, the approach of geobody seems to be a difficult metaphor. Taiwan is mostly conceptualized in the shape of a yam or a swimming whale. In addition to the morphological similarity between the aforementioned two symbols and the said island, interpretation on the metaphors was added. Yam stands for vitality as the early immigrants viewed themselves the successful survivors outside the pale of Chinese civilization. As for the geobody of the whale, it has become more popular in recent years due to its oceanic metaphor, in contrast to the continent-based discourses about the national identity of mainland China; it also possesses the ontological power of incorporating native Austronesian cultures. 


\section{P. Kang}

Nevertheless, the island of Taiwan finds it hard to mentally incorporate its offshore islets and archipelago as its continent-based counterpart does. How, especially, is Taiwan to incorporate its small island territories situated next to mainland China: Quemoy (Kinmen) and Matsu? Thus, the current study serves not only to improve our understanding of how islands are incorporated into continents in nationalist discourse, but also highlights how a de facto island state attempts to incorporate its own offshore territories as well, perhaps just as clumsily, in the context of a nationalist project.

\section{Acknowledgements}

I would like to thank Hung Wei-hau for his assistance in map-collecting and excellent cartographic works. I am also greatly indebted to the valuable comments from two anonymous reviewers and the editor. The paper is a revised version originally presented at the International Conference organized by the Islands Commission of the International Geographical Union (IGU), in collaboration with the Department of Human Geography, Lund University, on the island of Ven, Sweden, August 2010, and titled: Finding their Place: Islands in Social Theory. Any errors and mis-interpretations in the article remain only my own.

\section{References}

Anderson, B. (1991) Imagined Communities: Reflections on the Origin and Spread of Nationalism, New York, Verso.

Bartmann, B. (2008) 'Between De Jure and De Facto Statehood: Revisiting the Status Issue for Taiwan', Island Studies Journal, Vol. 3, No. 1, pp. 113-128.

Chen, Cheng-siang (1963) Taiwan: An Economic and Social Geography Vol. I, Taipei, Fu-min Geographical Institute of Economic Development.

Chou, Yu-sen (2003) 'A Study on the Construction of Taiwan City Walls in Chin(g) Dynasty', MA thesis, Dept. of Architecture, National Cheng-kung University, Taiwan.

Chung, Yi-ming (1997) Taiwan dili tuji (Collection of maps on geography of Taiwan), Taipei, Wu-ling.

Copper, J.F. (1996) Taiwan: Nation-State or Province?, Boulder CO, Westview Press.

Feuchtwang, S. (2008) 'Afterword', in Fang-Long Shih, S. Thompson, \& P. Tremlett (eds.) Re-writing Culture in Taiwan, London, Routledge, pp. 198-209.

Gold, T.B. (1994) 'Civil Society and Taiwan's Quest for Identity' in S. Harrell \& Huang Chün-chien (eds.) Cultural Change in Postwar Taiwan. Taipei, SMC, pp. 22-46. 
Herman, T. (1965) 'Reviewed work(s): Taiwan: An Economic and Social Geography by Cheng-Siang Chen', Geographical Review, Vol. 55, No. 2, pp. 301-303.

Ho Chin-chu (He Jinzhu) (1998) Taiwan dizhi (Topographical Gazetteer of Taiwan). Taipei: Longyin.

Hong, K. \& Murray, S.O. (2008) Looking Through Taiwan: American Anthropologists' Collusion with Ethnic Domination, Lincoln NE, University of Nebraska Press.

Ivarsson, S. (2008) Creating Laos: the making of a Lao space between Indochina and Siam, 1860-1945. NIAS Press.

Knapp, R. G. ed. (1980) China's Island Frontier: Studies in the Historical Geography of Taiwan. Honolulu HI, University of Hawaii Press.

Li Kuo-chi (1982) Modernization in China: 1860-1916. A Regional Study of Social, Political and Economic Change in Fukien, Chekiang and Taiwan (in Chinese). Nankang, Academia Sinica.

Markley, R. (2007) 'Global Analogies: Cosmology, Geosymmetry, and Skepticism in some Works of Aphra Behn' in J. Cummins \& D. Burchell (eds.) Science, Literature and Rhetoric in Early Modern England, Burlington MA, Ashgate, pp. 189-219.

Murray, S.O. \& Hong, K. (1994) Taiwan Culture, Taiwanese Society: A Critical Review of Social Science Research Done on Taiwan. Lanham MD: University Press of America.

Ng, Yeh Tak (1973) 'Social Geography: A Survey of Theories and Methodologies', United College Journal, Vol. 11, No. 1, pp. 155-168.

Reid, A. (1988) Southeast Asia in the Age of Commerce 1450-1680, Vol. I: The Lands below the Winds, New Haven MA, Yale University Press.

Schendel, W. van (2002) 'Geographies of Knowing, Geographies of Ignorance: Jumping Scale in Southeast Asia' in P.H. Kratoska, R. Raben \& H.S. Nordholt (eds.) Locating Southeast Asia: Geographies of Knowledge and Politics of Space, Singapore, Singapore University Press, pp. 275-307.

Tremlett, P. (2009) 'Introduction: Re-writing Culture on Taiwan' in Fang-Long Shih, S. Thompson \& P. Tremlett (eds.) Re-writing Culture in Taiwan, London, Routledge, pp. $1-14$.

TWFC: Kao (1960) Taiwan fuzhi (Gazetteer of Taiwan Prefecture). Kao Kung-ch'ien, ed. 1694.

Winckler, E.A. (1994) 'Cultural Policy on Postwar Taiwan' in S. Harrell \& Huang Chün-chien (eds) Cultural Change in Postwar Taiwan, Taipei, SMC Publishing, pp. 47-68.

Winichakul, T. (1994) Siam Mapped: A History of the Geo-Body of a Nation. Honolulu HI, University of Hawaii Press. 


\section{P. Kang}

Wu Chih-chung (2006) 'Europe's view of Cuba and Taiwan', Taiwan News-EU PAGE, August 28, www.eusa-taiwan.org/News_Analysis/Taiwan\%20News\%20EU\%20PAGE/ TN\%20EU\%20PAGE2006.asp.

Wu, D. Yen-ho (1991) 'The Construction of Chinese and non-Chinese Identities', Daedalus, Vol. 120, No. 2, pp. 159-179. 